\title{
Acknowledgments
}

We thank Robert Paine for introducing us to each other and for so generously teaching us over the years (on many a wild, wet field trip) about the ecology and natural history of exposed rocky shores.

I thank Ellen Daniell, Harry Greene, Mark Harrington, Mark Moffett, Rachel Norton, Zack Powell, Alan Shanks, and Richard Strathmann for plowing through early drafts of this book and making many helpful suggestions. I am also grateful to my mentors in biomechanics, Stephen Wainwright, Steven Vogel, and John Currey, who started me along the research path that eventually led to this book. I appreciate the many field assistants who have helped me schlep electronic gear over slippery rocks down to the waves. Thanks to Scott Jackson for technical assistance and good humor in the face of deadline panics. Much of my research reported here was supported by grants from the National Science Foundation, by a Guggenheim Fellowship, and by a MacArthur Fellowship.

Mimi Koehl

Photography is, among other things, a form of visual scholarship. Constructing a book, and continually looking at the relationships of its pliant, evolving parts, is a building process. For encouraging both the builder and artist in me, I continue to hold a special place in my heart for the late Ann O’Hanlon.

I would like to thank everyone who helped me manage the abundant challenge of getting photographic gear to and around the intertidal site described in this book. In particular, I would like to thank Ryan Baldwin, without whom it would have been impossible to carry this project 
forward. I deeply appreciate his willingness to work any hour of the day or night in any sort of wet, windy, slippery, or otherwise trying conditions. I'm also grateful for his indispensable help carrying huge amounts of equipment — uncomplainingly — for miles at a stretch. Most important, Ryan's friendship, his extensive knowledge of photography, and his technical and aesthetic assistance have been an unfailing support throughout this project.

I would like to thank Laura Shapiro, who is consistently a most sensible and helpful guide in every direction of my work and the dearest of friends. Her contributions to this and other projects have been innumerable.

Finally, I would like to thank my husband, Bob Rosenfeld, and our son, Matthew, for their contributions to this book, many but not all of them age-related. A tide-driven work schedule makes for numerous domestic disruptions, and their tolerance has been admirable.

Anne Rosenfeld 


\section{Wave-Swept Shore}




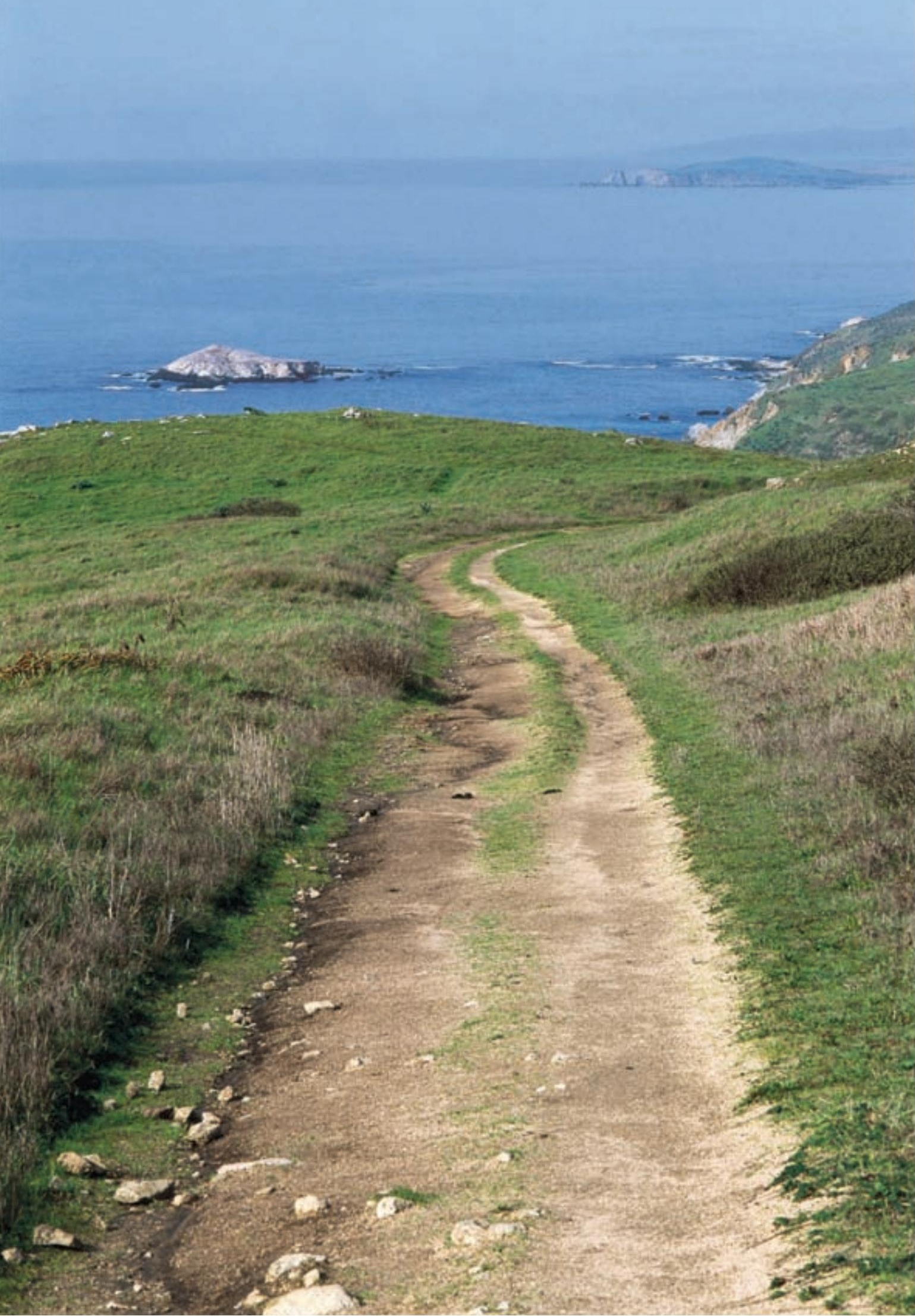

